\title{
Establishing and Testing a Quantitative Measure for Evolving Third-Place Characteristics
}

\author{
Michael Langlais, Florida State University, USA* \\ (iD) https://orcid.org/0000-0001-8892-2808 \\ Dana E. Vaux, University of Nebraska, Kearney, USA \\ (iD) https://orcid.org/0000-0003-1074-2625
}

\begin{abstract}
Third places offer and promote social experiences beneficial for building interpersonal relationships. This study has two goals: 1) establish a scale that tests if an environment is characteristic of third place characteristics and 2) use this scale with four virtual environments (Facebook, Snapchat, Instagram, and Twitter) to test the proficiency of third place characteristics as representative of virtual third places. A research-informed scale was created and tested with a sample of 354 participants. Confirmatory factor analysis verified a nine-factor solution, with each subscale reporting acceptable reliability (range: .89 to .96 ). This scale was tested with 140 participants to verify if certain social media qualified as third places. MANOVAs revealed that Facebook adheres most closely to the majority of third place characteristics, followed by Snapchat, Instagram, and Twitter, respectively. The proposed scale can be used with other virtual environments to measure if they qualify as third places.
\end{abstract}

\section{KEYWORDS}

Third place, Social media, Social capital

\section{INTRODUCTION}

Oldenburg and Brissett (1982) proposed third places as a solution to an apparent loss of community in American culture, arguing that these physical environments offer important opportunities for social relationships beyond work colleagues and family. The eight characteristics of traditional third places that contribute to the sociability of a third place environment include the following (Oldenburg, 1999, p. 22-41; Vaux \& Langlais, in press):

Neutral: Informal settings, the primary attribute of a third place is to promote sociability.

Levelers: No membership is required; all are welcome.

Conversation Main Activity: The main activity of a third place is conversation.

Accessibility and Accommodation: Third places are physical locations easily accessed in a user's daily routine. 
Regulars: Third places are often frequented as a customary practice so that individuals are known to one another.

Low Profile: Third places are ordinary physical environments.

Playful Mood: Playful banter keeps conversation light and friendly.

Home Away from Home: Third places are a home away from home for patrons.

Physical environments that meet a majority of these characteristics are representative of a third place (Vaux, 2014; Waxman, 2006).

The characteristics proffered by Oldenburg identify whether physical environments can be third places, but recent studies suggest that virtual environments also serve as third places. "Oldenburg's conceptualization [of the third place] has been used consistently to describe the communication of computer-mediated contexts such as chatrooms and multiuser environments" (Soukup, 2009, p. 421). Virtual third places are computer-generated platforms on the internet that simulate face-to-face interactions. The use of technology to communicate is not the defining factor of a virtual third place. Individuals use phones, email and texting to communicate through technology but these do not serve as third places because they are not multiuser domains where "community is formed, maintained and revitalized" (Kendall, 2002 cited in Soukup, 2009, p. 424).

This debate was initially discussed as researchers sought to understand how early virtual environments might be a new way of forming social communities (Rheingold, 1993; Wellman \& Gulia, 1999; Wuthnow, 1999). For example, Putnam and Feldstein (2003) argued that communities and relationships can be built through Craigslist.com, an early internet site used to sell merchandise, meet romantic partners, or find roommates. Later, Soukup (2006) elaborated on the notion of virtual communities and suggested that they could be third places. He states, "Computer networks can provide the means to create new 'virtual' places that offer functionally similar forms of localized informal interaction" (p. 438). Subsequently, a number of studies have identified virtual environments that can also be third places. For instance, McArthur and White (2016) introduced how conversations on Twitter are representative of third places and Ducheneaut and Moore (2007) discussed how Massively Multiplayer Online Gaming (MMOG) represent third places, both using traditional third place characteristics as a measure. Essentially third places may not be limited to physical "places," but more broadly inclusive of various "spaces," whether virtual or physical (Purnell, 2015).

Other recent studies have argued that using traditional third place characteristics focused on physical environments to measure sociability in virtual environments is not a sensible approach (Vaux \& Langlais, in press; Soukup, 2006). For instance, Soukup (2006) argues that virtual environments are viable third places when individuals can gather and socialize around a local network, and traditional third place characteristics may not describe virtual socializing, despite meeting the same goals as physical third places. Memarovic et al. (2014) elaborates on this debate by adding three characteristics to Oldenburg's (1999) eight traditional third place characteristics, which includes discovering a third place in advance, declaring type of supported social activity, and extending engagement with/within a third place. In essence, these researchers argued that individuals could access a virtual third place, while in a physical third place. Each of these studies has shown that virtual third places do exist but concur that the traditional third place characteristics are insufficient to designate if a virtual environment represents a third place. The ways that individuals socialized when Oldenburg performed his research is not the same way that individuals socialize in current society, which involves socializing in both physical and virtual environments. Therefore, third place characteristics needed updating to reflect current socializing trends. Based on this incongruity, traditional third place characteristics have been updated to represent current socializing trends (Vaux \& Langlais, in press; see Table 1 for an overview).

These characteristics are not inclusive of all social behavior, but identify the most prominent characteristics of socializing in third places. With research on physical environments, most studies examine third places through observational data to determine if an environment is a third place. This approach would not be feasible with virtual environments, as they are difficult to observe. Additionally, 
Table 1. Summary of third place characteristics and evolving trends via Facebook

\begin{tabular}{|c|c|c|c|}
\hline & Characteristic & $\begin{array}{l}\text { Evolving Third Place } \\
\text { Characteristics }\end{array}$ & Definition \\
\hline 1 & Neutral & $\begin{array}{l}\text { Relationship Initiation and } \\
\text { Maintenance }\end{array}$ & $\begin{array}{l}\text { The environment promotes social } \\
\text { relationships by providing opportunities } \\
\text { to maintain existing relationships and/or } \\
\text { establish new ones }\end{array}$ \\
\hline 2 & Leveler & Equalizer & $\begin{array}{l}\text { Individuals have equivocal opportunities } \\
\text { to socialize with others in an } \\
\text { environment }\end{array}$ \\
\hline 3 & Conversation Main Activity & $\begin{array}{l}\text { Communication Main } \\
\text { Activity }\end{array}$ & $\begin{array}{l}\text { Conversation is the primary activity and } \\
\text { the means to form social relationships in } \\
\text { an environment }\end{array}$ \\
\hline 4 & Accessibility/Accommodation & $\begin{array}{l}\text { Active and Passive } \\
\text { Engagement }\end{array}$ & $\begin{array}{l}\text { Individuals can be active participants in } \\
\text { an environment or be passively engaged } \\
\text { through observations }\end{array}$ \\
\hline 5 & Regulars & Reciprocity & $\begin{array}{l}\text { An expected responsiveness between } \\
\text { individuals exists in a third place } \\
\text { environment }\end{array}$ \\
\hline 6 & Low Profile & People Over Place & $\begin{array}{l}\text { Individuals focus more on social } \\
\text { connection than the specific attributes } \\
\text { of the environment }\end{array}$ \\
\hline 7 & Playful Mood & Playful Mood & $\begin{array}{l}\text { Individuals seek wit and humor when } \\
\text { socializing with others }\end{array}$ \\
\hline 8 & Home Away from Home & $\begin{array}{l}\text { Cognitive Separation and } \\
\text { Reprieve }\end{array}$ & $\begin{array}{l}\text { Individuals can disconnect from a } \\
\text { stressful environment and connect } \\
\text { to another environment in a way } \\
\text { that provides respite from routine, } \\
\text { monotony, or isolation }\end{array}$ \\
\hline 9 & Discover in Advance & \multirow{3}{*}{$\begin{array}{l}\text { Third Place Within a Third } \\
\text { Place }\end{array}$} & \multirow{3}{*}{$\begin{array}{l}\text { Individuals can access a virtual third } \\
\text { place while being in a physical third } \\
\text { place environment }\end{array}$} \\
\hline & $\begin{array}{l}\text { Declaring Type of Supported Social } \\
\text { Activity }\end{array}$ & & \\
\hline & $\begin{array}{l}\text { Extending engagement with/within a } \\
\text { third place }\end{array}$ & & \\
\hline
\end{tabular}

as argued in the literature, socializing in physical third places may not equate to socializing in virtual third places.

In order to advance research on third places, quantitative approaches are needed to increase universality when determining if an environment is a third place (Soukup, 2006). Therefore, this study expands on the updated, evolving third place characteristics by creating and testing a scale that looks to measure each evolving third place characteristic with SNS, which are virtual environments. Although this study focuses on virtual third place characteristics resulting from evolving socializing trends, the results should provide a foundation for creating measures that test both virtual and physical environments.

Third place theory, specifically evolving third place characteristics, is similar and different compared to uses and gratifications theory (UGT). UGT focuses on how and why individuals use social media (Ruggiero, 2000). Third place theory focuses on how the use of the environment, whether virtual or physical, impacts relational well-being. Although gratification is associated with improvements in well-being within both theories, the current study examines the environment and experiences of engagement in social media for well-being. This is a difference with UGT, which 
focuses on internal motivations for using social media, compared to third place theory, which seeks to understand how the environment contributes to the motivation for using social media. This study takes a broader view to understand how individuals' use of social media creates "social spaces outside professional and familial roles for the purpose of informal social interaction" (Soukup, 2009, p. 424). We compare these theories not to critique them, but to show how they can potentially build off each other to understand the relationship between motivations for using social media use and increases in well-being through evolving third place characteristics. The combined social experience of the users delineates the characteristics outlined in this paper that define a virtual third place.

In addition to creating a scale that quantifies virtual third places, this study seeks to identify whether four different virtual environments (Facebook, Snapchat, Instagram, and Twitter) are representative of third places as defined by evolving third place characteristics. These four social media platforms were selected because they are the most widely used SNS (Pew Research Center, 2018). To date, many studies on social media rely exclusively on Facebook as their source of analysis. Some of these studies have discussed that Facebook meets many of the traditional characteristics of third places (i.e., Memarovic et al., 2014; Rao, 2008) and serves the primary purpose of a third place by building social capital (Ellison et al., 2007; Phua et al., 2017; Sinclair \& Grieve, 2017). As for other SNS, there is much less information. An exception is a study by McArthur and White (2016) who illustrate that conversations (i.e., such as private messaging) on Twitter can qualify as third places by meeting some of the traditional third place characteristics. However, the most common behaviors on Twitter are not private messaging (Smith, 2016). There is even less research about whether Snapchat and Instagram can serve as third places. A method to quantify the use of SNS as third places would be useful since current measures use traditional third place characteristics, which are an insufficient assessment of virtual environments (Soukup, 2016; Memarovic et al., 2014; Wright, 2012).

\section{MATERIALS AND METHOD}

The first goal of this study is to create a scale that measures evolving third place characteristics in virtual environments. The second goal is to use the scale to examine if current SNS (Facebook, Snapchat, Instagram, and Twitter) adhere to evolving third place characteristics. More explicitly, we hypothesize that the evolving third place characteristics will be positively associated with all four social media platforms, but most clearly align with Facebook compared to other social media platforms, consistent with the reviewed literature above. To accomplish the first goal, a scale was created that measured each of the nine evolving third place characteristics. Example items include "How often do you use social media to meet new friends?" (relationship initiation and maintenance); "How often do you use social media to connect with someone you know who you cannot meet in person due to geographical constraints (i.e., they don't live near you)?" (equalizer); "How often do you use social media in addition to communicating face-to-face with the same person?" (communication main activity); "How often do you use social media to engage with others?" (active and passive engagement); "How often do you expect others to respond to you on social media?" (reciprocity); "How often do you personalize your profile on social media?" (people over place); "How often do you use social media to express humor to others?" (playful mood); "How often do you use social media to relax or unwind?" (cognitive separation and reprieve); and "How often do you use the following social media in an environment where you can meet others face-to-face?" (third place within a third place). These questions were created through a critical examination of the literature on physical and virtual third places (i.e. McArthur \& White, 2016; Memarovic et al., 2014), noting recommendations from researchers concerning ways to study virtual environments (Soukup, 2006). Responses ranged from 1 (never) to 7 (all the time).

Before utilizing this scale, construct validity had to be tested. To complete this task, participants completed an online survey answering questions regarding evolving third place characteristics in the context of social media. Participants were recruited via word-of-mouth from the primary investigators 
to complete a brief, online survey regarding their motivations for using social media. This approach led to 354 participants completing the online survey; however, only 323 were used in the current investigation as 31 participants reported no SNS use. The average age of participants in this study was 35.95 ( $S D=17.20)$ and most participants were female (78.6\%). Additionally, the majority of participants were white (92.3\%) with others representing Hispanic (3.4\%), African American/Black (1.0\%), Asian/Pacific Islander (1.9\%), and other (1.4\%), and most were from the Midwestern United States $(85.1 \%)$.

Because the created items had not been used previously, the factorability of all 34 items was examined using established criteria for the factorability of a correlation (Bryant \& Yarnold, 1995; Tabachnick \& Fiddell, 2007). First, 32 out of the 34 items were correlated at least .3 with one another, suggesting reasonable factorability. Second, the Kaiser-Meyer-Olkin measure of sampling adequacy was .815, which is above the recommended value of .6 (Cerny \& Kaiser, 1977). Additionally, Bartlett's test of sphericity was significant $\chi^{2}(561)=2144.92, p<.001$. Given these indicators, exploratory factor analysis was suitable with all 34 items. Principal axis factoring was conducted using direct oblimin rotations. Since there were nine evolving third place characteristics, the authors fixed the number of factors to nine. This solution was verified when nine factors were found with eigenvalues greater than one. Through this approach, $73.06 \%$ of the variance was explained by the nine fixed factors (see Table 2). In order to determine construct and content validity, we examined various statistical information. First, all items had primary loadings over .5. Factor loading matrices are presented in Table 3. Additionally, reliability for each scale was acceptable (Range: .89 to .96). Applying the procedures offered by Westen and Rosenthal (2003), we compared the means and correlations of the calculated nine factors with two studies examining third places in a virtual context (Memarovic et al., 2014; Langlais \& Vaux, in press). We first examined the correlation of the entire scale to these previous studies, and then analyzed the intercorrelations among the variables within each scale and compared those correlations to the intercorrelations between similar factors in the other two scales. Correlations between scales ranged from .76 to .88 , and the correlations within scales ranged from .54 to .85 , suggesting adequate construct validity. Subsequently, this scale was applied to four different social media platforms (Facebook, Snapchat, Instagram, and Twitter; i.e., the word "social media" was changed in the subsequent study survey to reflect individuals' use for each one of the four different social media being studied). One hundred and forty participants were recruited using word-of-mouth methods to complete an online survey applying each of these items with all four hypothesized SNS. The average age of participants in this wave of data collection was $32.19(S D=17.01)$. Approximately $86.4 \%$ of participants were female and $72.8 \%$ of participants were White or Caucasian, whereas the remainder were Hispanic (7.1\%), American Indian or Alaska Native (3.6\%), Asian (2.1\%), Middle Eastern (0.7\%), Black or African American (0.7\%), other (2.9\%), and 0.7\% preferred not to say. This research was approved by the appropriate Institutional Review Board.

\section{RESULTS}

First, one-sample $t$-tests against a score of 4.00 (the median of the scale) was used to determine if the SNS is representative of that characteristic. Results of these analyses can be found in Table 4. According to these results, Facebook is significantly higher than the median on three of the nine characteristics: relationship initiation and maintenance, reciprocity, and third place within a third place. Snapchat was significantly higher for reciprocity, but not with any other characteristics. Not only were Instagram and Twitter not positively associated with third place characteristics, but Twitter was significantly lower than the median on six of the nine characteristics and Instagram was significantly lower on five of the nine characteristics; Snapchat was only significantly lower on two of the nine characteristics. These findings reveal that Facebook meets the majority of third place characteristics, followed by Snapchat, Instagram, and Twitter respectively. 
Table 2. Variance and eigenvalues explained through factor analyses.

\begin{tabular}{|l|l|l|l|}
\hline Factor & Total & \% of Variance & Cumulative \% \\
\hline 1 & 5.68 & $39.02 \%$ & $39.02 \%$ \\
\hline 2 & 2.43 & $11.43 \%$ & $50.45 \%$ \\
\hline 3 & 1.89 & $7.55 \%$ & $58.00 \%$ \\
\hline 4 & 1.78 & $4.94 \%$ & $62.94 \%$ \\
\hline 5 & 1.55 & $3.01 \%$ & $65.95 \%$ \\
\hline 6 & 1.41 & $2.74 \%$ & $68.69 \%$ \\
\hline 7 & 1.17 & $1.94 \%$ & $70.63 \%$ \\
\hline 8 & 1.08 & $1.31 \%$ & $71.94 \%$ \\
\hline 9 & 1.01 & $1.12 \%$ & $73.06 \%$ \\
\hline Note: We did not present factors 10 or greater, as the eigenvalues were all less than 1.0, and for parsimony. \\
\hline
\end{tabular}

Next, MANOVAs were conducted to examine mean differences across SNS for all nine evolving third place characteristics. Results of these analyses are presented in Table 5. Based on these findings, Facebook has significantly higher means for seven of the nine characteristics compared to the other SNS. Snapchat reports higher means for six of the nine characteristics compared to Instagram and/or Twitter. Instagram also exhibits higher means than Twitter in five of the nine characteristics.

Based on these analyses, there is strong quantitative support that individuals use Facebook as a virtual third place. Additionally, there is quantitative support that Snapchat and Instagram adheres to some of the evolving characteristics of third places, but not all of them. Last, there is no quantitative support that illustrates that Twitter is a third place based on evolving third place characteristics. Six of the nine evolving characteristics were associated with Facebook, and were significantly higher than other SNS. Reciprocity was significantly associated with Snapchat and Instagram was significantly associated with third place within a third place. Based on study data, Facebook most clearly aligned with evolving third place characteristics, followed by Snapchat and Instagram, and Twitter was not significantly associated with any of the evolving third place characteristics.

Following the survey, existing literature was examined to see if any research studies would provide further evidence that these SNS represent virtual third places as defined by these characteristics. This information is subsequently presented and organized by SNS in order of popularity (Facebook, Snapchat, Instagram, and Twitter; Lenhart, 2015) and availability of existing literature. The known literature is discussed to verify if the information supports any of the evolving characteristics of third places. Throughout the review, the evolving characteristics are identified by numerical order listed in Table 1.

\section{Facebook}

Facebook has been extensively investigated in terms of the benefits of third places with research providing support for nearly all nine evolving third place characteristics. One study found that individuals cited Facebook as their primary tool for meeting new people (Fox et al., 2013) [\#1 on our list: relationship initiation and maintenance] and another described Facebook as a beneficial way for individuals to learn about new friends (Hsu et al., 2011). Additionally, Facebook use has been linked to the formation and maintenance of romantic relationships (Fox et al., 2013; LeFebvre et al., 2015). Next, there is support that Facebook meets the criteria of equalizer [\#2]. The mission of Facebook, as stated by Facebook (2018) is "to give people the power to share and make the world more open and connected." Facebook is not only popular in the United States, but also in the Eastern 
Table 3. Confirmatory Factor Analysis for Evolving Third Place Characteristics

\begin{tabular}{|c|c|c|c|c|c|c|c|c|c|c|c|}
\hline Characteristic & & $\alpha$ & 1 & 2 & 3 & 4 & 5 & 6 & 7 & 8 & 9 \\
\hline \multirow[t]{4}{*}{$\begin{array}{l}\text { Relationship Initiation and } \\
\text { Maintenance }\end{array}$} & Meet new friends & .89 & .51 & -.20 & .17 & -.06 & .11 & .18 & -.03 & .14 & .15 \\
\hline & Learn about friends & & .78 & .17 & -.01 & -.29 & -.01 & -.14 & -.01 & .14 & -.10 \\
\hline & Keep in touch with friends & & .72 & .24 & -.06 & -.21 & -.15 & .02 & .09 & .01 & .11 \\
\hline & Keep in touch with family & & .55 & .39 & .02 & .17 & -.01 & -.02 & .28 & .04 & .01 \\
\hline \multirow[t]{4}{*}{ Equalizer } & $\begin{array}{l}\text { Communicate with friends } \\
\text { long distance }\end{array}$ & .91 & .32 & .56 & -.08 & .14 & -.09 & -.11 & -.22 & .00 & .14 \\
\hline & $\begin{array}{l}\text { Communicate with } \\
\text { acquaintances long distance }\end{array}$ & & .24 & .42 & .39 & .06 & .07 & -.03 & .03 & -.08 & .07 \\
\hline & $\begin{array}{l}\text { Communicate with family } \\
\text { long distance }\end{array}$ & & .19 & .58 & .17 & .28 & .09 & -.27 & -.01 & .04 & .03 \\
\hline & Communicate not in-person & & .34 & .53 & .39 & .29 & -.18 & .11 & .14 & .07 & -.23 \\
\hline \multirow[t]{4}{*}{$\begin{array}{l}\text { Communication Main } \\
\text { Activity }\end{array}$} & $\begin{array}{l}\text { Add to face-to-face } \\
\text { communication }\end{array}$ & .90 & -.13 & .10 & .79 & -.07 & -.04 & .06 & -.01 & .08 & .01 \\
\hline & $\begin{array}{l}\text { Arrange a face-to-face } \\
\text { encounter }\end{array}$ & & .16 & .17 & .61 & -.11 & .19 & .08 & -.31 & .14 & .16 \\
\hline & $\begin{array}{l}\text { Rely on to initiate } \\
\text { conversation }\end{array}$ & & .17 & .19 & .72 & .04 & .12 & .23 & .09 & .09 & -.03 \\
\hline & Learn about social events & & .18 & .28 & .72 & -.23 & .07 & -.14 & .13 & -.08 & -.01 \\
\hline \multirow[t]{3}{*}{$\begin{array}{l}\text { Active and Passive } \\
\text { Engagement }\end{array}$} & Engage in conversations & .92 & -.22 & .20 & .04 & .82 & .01 & .27 & -.20 & -.08 & .12 \\
\hline & Observe others' conversations & & .24 & -.04 & .24 & .65 & -.09 & -.02 & -.23 & -.23 & -.02 \\
\hline & Observe others' activities & & .21 & .02 & .09 & .82 & -.14 & .05 & -.12 & .02 & -.26 \\
\hline \multirow[t]{4}{*}{ Reciprocity } & Check social media & .91 & .18 & .10 & -.27 & -.08 & .77 & .06 & .07 & -.10 & .08 \\
\hline & $\begin{array}{l}\text { Check within } 15 \text { minutes of } \\
\text { waking up }\end{array}$ & & .19 & -.07 & -.06 & -.37 & .67 & -.10 & .01 & .07 & -.02 \\
\hline & Expect others to respond & & .22 & -.02 & -.16 & .06 & .77 & .10 & .01 & .21 & .11 \\
\hline & Notice if no response & & .17 & -.07 & -.16 & .21 & .71 & .20 & .26 & .07 & .08 \\
\hline \multirow[t]{3}{*}{ People Over Place } & Personalize profile & .92 & .11 & -.17 & .05 & .12 & .22 & .75 & .07 & -.25 & .18 \\
\hline & Update profile & & -.01 & -.19 & -.08 & -.01 & .32 & .77 & .09 & -.18 & .13 \\
\hline & Post personal photos & & -.13 & .06 & -.39 & .16 & .24 & .72 & .04 & -.05 & -.22 \\
\hline \multirow[t]{3}{*}{ Playful Mood } & Express humor & .89 & -.14 & -.21 & -.07 & .24 & .11 & -.21 & .76 & .20 & -.03 \\
\hline & Share something humorous & & .33 & -.28 & -.13 & .16 & .14 & -.21 & .81 & .15 & -.01 \\
\hline & Flirt with others & & -.34 & -.34 & .37 & -.04 & .11 & .06 & .58 & .05 & .04 \\
\hline \multirow[t]{5}{*}{$\begin{array}{l}\text { Cognitive Separation and } \\
\text { Reprieve }\end{array}$} & Relax and unwind & .96 & .08 & -.07 & .00 & -.06 & -.27 & -.16 & .01 & .81 & .01 \\
\hline & Take a break & & .09 & -.21 & -.21 & .09 & -.36 & .05 & -.03 & .80 & .09 \\
\hline & Diversion & & -.06 & -.21 & .17 & .13 & -.39 & -.12 & .03 & .66 & .09 \\
\hline & Relieve stress & & -.07 & -.39 & .01 & .12 & -.34 & -.07 & .00 & .77 & .10 \\
\hline & $\begin{array}{l}\text { Feel more comfortable in } \\
\text { awkward situations }\end{array}$ & & .15 & -.32 & .12 & -.20 & .08 & .07 & .15 & .71 & -.03 \\
\hline \multirow[t]{4}{*}{$\begin{array}{l}\text { Third Place Within a Third } \\
\text { Place }\end{array}$} & Use in a social environment & .91 & .19 & -.19 & .19 & -.12 & .10 & -.06 & .15 & -.11 & .71 \\
\hline & "Like" content & & .33 & .09 & -.18 & -.04 & -.06 & .25 & -.03 & -.21 & .74 \\
\hline & Share content & & -.21 & -.15 & -.06 & .39 & .12 & .21 & -.20 & -.21 & .74 \\
\hline & Access on mobile device & & -.03 & -.13 & -.33 & -.13 & .02 & -.06 & .03 & .07 & .77 \\
\hline
\end{tabular}


Table 4. One-sample t-tests examine strength of evolving third place characteristics $(\mathrm{N}=140)$



Note: Bolded statistics are means statistically higher than 4 , meaning that they are representative of a third place characteristic.

${ }^{* * *} p<.001 ;{ }^{* *} p<.01 ;{ }^{*} p<.05$. 
Table 5. MANOVA results for each third-place characteristic by SNS

\begin{tabular}{|c|c|c|c|c|c|}
\hline Characteristic & $\begin{array}{l}\text { Facebook }(n= \\
\text { 137) }\end{array}$ & $\begin{array}{l}\text { Snapchat ( } n \\
=112)\end{array}$ & $\begin{array}{l}\text { Instagram }(n \\
=117)\end{array}$ & $\begin{array}{l}\text { Twitter }(n \\
=87)\end{array}$ & $F(3,110)$ \\
\hline $\begin{array}{l}\text { Relationship Initiation and } \\
\text { Maintenance }\end{array}$ & $4.41(1.41) \mathrm{a}$ & $3.69(1.94) b$ & $3.72(2.68) \mathrm{b}$ & $\begin{array}{l}2.68(1.74) \\
\mathrm{c}\end{array}$ & $17.12 * * *$ \\
\hline Equalizer & $3.73(1.31) \mathrm{a}$ & $3.14(1.80) \mathrm{b}$ & $3.12(1.65) b$ & $\begin{array}{l}2.33(1.55) \\
\mathrm{c}\end{array}$ & $9.54 * * *$ \\
\hline Communication Main Activity & $4.07(1.36) \mathrm{a}$ & $3.70(1.99) \mathrm{b}$ & $2.83(1.53) \mathrm{c}$ & $\begin{array}{l}2.50(1.67) \\
\mathrm{c}\end{array}$ & $11.91 * * *$ \\
\hline Active and Passive Engagement & $4.14(1.55) \mathrm{a}$ & $3.65(1.93) \mathrm{b}$ & $3.48(1.71) \mathrm{b}$ & $\begin{array}{l}3.35(2.12) \\
\mathrm{b}\end{array}$ & $6.72 * *$ \\
\hline Reciprocity & $4.46(1.52) \mathrm{a}$ & $4.42(2.10) \mathrm{a}$ & $3.89(1.78) b$ & $\begin{array}{l}3.28(1.99) \\
\mathrm{c}\end{array}$ & $10.63^{* * *}$ \\
\hline People Over Place & $3.54(1.45) \mathrm{a}$ & $3.23(1.78) \mathrm{a}$ & $3.33(1.66) \mathrm{a}$ & $\begin{array}{l}2.52(1.68) \\
\mathrm{c}\end{array}$ & $7.54 * *$ \\
\hline Playful Mood & $3.26(1.44) \mathrm{a}$ & $3.82(1.97) b$ & $3.09(1.70) \mathrm{a}$ & $\begin{array}{l}3.25(2.04) \\
\mathrm{a}\end{array}$ & $3.22 *$ \\
\hline Cognitive Separation and Reprieve & $3.82(1.66)$ & $3.77(2.01)$ & $3.92(1.89)$ & $3.57(2.27)$ & 1.45 \\
\hline Third Place Within a Third Place & $4.37(1.39) \mathrm{a}$ & $3.88(1.80) \mathrm{b}$ & $4.15(1.73) \mathrm{a}$ & $\begin{array}{l}3.60(2.00) \\
b\end{array}$ & $3.12 *$ \\
\hline
\end{tabular}

hemisphere, with 300 million daily active users in Asia and 233 million daily active users in Europe (Smith, 2016). Studies illustrate that Facebook is the primary SNS used to interact with friends, family members, acquaintances, and also strangers (Billedo et al., 2015; Sinclair \& Grieve, 2017).

Studies examining motivations for Facebook use illustrate that communication ranks as a primary reason for Facebook use [\#3] (Bargh \& McKenna, 2004; Sheldon, 2008). People use Facebook to stay connected with friends and family, as well as broader social spheres to discover what is going on in the world, and to share and express what matters to them through conversational posts, comments, and messages both within and outside of networks (Facebook, 2018). According to Park and colleagues (2011), self-disclosure on Facebook encourages communication from others. Additionally, individuals may passively view content by themselves, engage in active conversation with others, or engage in passive conversation with others, such as posting statuses or "liking" others' information on Facebook [\#4]. Moreover, users can login to Facebook around the clock, from a computer, tablet, or smart phone from any location with internet access. When individuals send someone a message, "like" a post, or respond to someone else's messages, posts, or comments on Facebook, reciprocity is expected [\#5]; however, there are no studies that support whether reciprocity occurs.

The primary interest for Facebook use is to connect to people, regardless of place [\#6]. Facebook also provides opportunities for playful mood [\#7]. Individuals often include emojis and humorous expressions to their posts. One study found that $51.4 \%$ of expressions on Facebook contain "haha" and $1.9 \%$ of Facebook posts contain "lol", an acronym for 'laugh out loud' (Smith, 2016). Research indicates that interaction on Facebook cognitively separates individuals from the context of their present physical environment [\#8] (McArthur, 2016). Individuals feel comfortable logging in and viewing a variety of content on Facebook, which $67 \%$ of users say provides them with current news and stories that are personally relevant (Smith, 2016). As of May 2013, there was an average of 4.5 billion "likes" on Facebook a day (Zephoria, 2016), illustrating that many individuals "like" content and that "liking" content occurs in various contexts. Individuals create events, invite friends to events 
or places, or view comments pertaining to events and places without being in that specific physical location, thus participating in a virtual third place, either actively or passively [\#9]. Generally, there is support in the literature that Facebook is representative of a majority of the evolving third place characteristics.

\section{Snapchat}

Snapchat functions differently than Facebook in that material shared is ephemeral, meaning that content disappears after it is viewed. The goal of Snapchat is to reinvent the camera "to improve the way people live and communicate" [\#3] (Snapchat, 2017). Individuals use Snapchat by sending "snaps," which are pictures and videos, to friends in their social network. Each photo and video can be edited to add filters, emojis, text, or other content. The content is often more personal and direct compared to other SNS. One study found that the majority of individuals use Snapchat to send "funny content" [\#7] (Bosker, 2014). Individuals check Snapchat multiple times a day, typically averaging approximately 25 to 30 minutes daily [\#4] (Carson, 2016). Although research is limited, there is support that Snapchat, despite being ephemeral, promotes communication and provides a sense of community with a small network of individuals [\#3, \#5]. Research illustrates individuals use Snapchat more to maintain relationships than to initiate them, and that networks on Snapchat are significantly smaller than networks on Facebook (Vaterlaus et al., 2016). However, there is some evidence that Snapchat provides a means to self-disclose in order to learn more about others [\#1] (Phua et al., 2017). Other studies show that Snapchat is used to communicate with others, both proximally and far away [\#6], and the primary function for using Snapchat is for entertainment [\#7] (Punyanunt-Carter et al., 2017). Also, Snapchat doesn't have a profile, but is connected to Bitmoji, another application that allows individuals to create a cartoon character of one's self that can be used to promote interactions with others [\#7] (Newton, 2017). One feature of Snapchat is the "Story" function, which allows individuals to post snaps for their social network to see. Research shows that individuals spend more time sending and receiving snaps than posting snaps to their story [\#8] (Piwek \& Joinson, 2016). Individuals are most likely to send and receive snaps from a close friend and spend most of their time communicating on Snapchat while at home (Piwek \& Joinson, 2016). The home environment becomes a third place (Purnell, 2015) as it hosts a virtual third place, supporting third place within a third place [\#9].

\section{Instagram}

Instagram is a photo-sharing application that allows individuals to privately or publicly share pictures with one's social network. Individuals can also message other users through Instagram. The creators of Instagram described three problems they wanted to solve via their application: lack of quality photos for online posting; the inability to share photos on multiple SNS; and the inefficiency of uploading photos (Chen, 2015). Although the application has been around since 2010, there is little research on Instagram in the context of third places. However, some studies provide evidence that Instagram may meet some of the evolving characteristics of third places.

Instagram has been linked to bridging social capital, but not as much to bonding social capital [\#1] (Phua et al., 2017). Other studies illustrate that the behaviors engaged on Instagram are not meant for forming or maintaining relationships, but rather to seek "likes" from one's social network [\#4] (Dumas et al., 2017). Additionally, given that the goal of Instagram is to post and share pictures, it is common for participants to passively view content, known as "peeking" [\#4], while the motivations associated with using Instagram were for social interaction, archiving, self-expression, and escapism [\#8]. The few existing studies on Instagram illustrate that individuals do not use this SNS to directly communicate with others despite that being an available feature available on Instagram, which reinforces its use to primarily observe others, rather than seek, maintain, or initiate relationships as a third place. 


\section{Twitter}

Twitter has been examined in the context of third places. McArthur and White (2016) used textual analysis to find support that conversations on Twitter are representative of third places based on Oldenburg's traditional characteristics. Essentially, these authors found that Twitter chats predominantly adhered to traditional third place characteristics. The current study expands on this discussion to see if Twitter would qualify as a third place using the evolving characteristics of third places and focusing on multiple Twitter features. The focus on Twitter chats may be overemphasized as Twitter conversations are not a predominant behavior on Twitter [\#3]. Instead, individuals often use Twitter to communicate with a general audience, without expectation of reciprocity by posting "tweets," which are posts that are limited to 140 characters and can be seen by a private or public audience. However, while $26 \%$ of Twitter users tweet to a general audience (public or private), $6 \%$ retweet another individual's tweet, and 68\% of users reply to a tweet [\#5], (Boyarsky, 2017).

One study found that individuals primarily use Twitter to read other peoples' tweets, with only $37 \%$ reporting that they post information or communicate with others regularly on Twitter, while $36 \%$ of Twitter users log in daily and 24\% log in weekly [\#4] (Rosenstiel et al., 2015; Duggan et al., 2015). Another study found that nearly $80 \%$ of Twitter users report using Twitter on their phones, meaning they can access the SNS wherever they have their phones [\#9] (Rosenstiel et al., 2015). Research on Twitter links the SNS to bonding social capital [\#1] (Phua et al., 2017), but is otherwise unrelated to forming or maintaining relationships (Blight et al., 2017).

\section{DISCUSSION}

This study had two goals. First, this study created and tested a quantitative measure of evolving third place characteristics that can be used with virtual environments. This scale was established and displayed high content and construct validity. Second, the study applied this scale to determine whether four different SNS qualify as virtual third places. As results indicate, socializing in the twentyfirst century is evolving, as socialization occurring in third places include virtual environments. Past theoretical frameworks have measured third places based on characteristics developed for the physical environment when it is evident that certain virtual environments challenge these theories to change and coincide with current societal and technological shifts. In this context, identifying third place characteristics relevant to virtual environments may reflect current social behaviors.

While studies exist that make connections between virtual environments and traditional third place characteristics, no studies appear to offer a quantitative framework of measuring virtual third places that can be applied across multiple SNS. The results of this study increase understanding of evolving third place characteristics and how to measure them in the virtual context by establishing a quantitative scale. In order to advance research on third places, studies should find ways to adapt this scale to examine both virtual and physical environments. Additionally, the current study illustrates that Facebook, Snapchat, Instagram, and Twitter serve as third places to varying degrees. These findings align with the primary aim of third places, which is sociability.

Regarding each SNS, results of this study demonstrate that Facebook consistently adheres with evolving third place characteristics. This finding is consistent with past studies examining this association (i.e., Langlais \& Vaux, in press) and other studies that make connections between Facebook third place characteristics and benefits (Fox et al., 2013; Rao, 2008; Wright, 2012). Individuals appear likely to socialize with others actively and passively on Facebook, which is the primary aim of third places. Individuals can access Facebook anywhere, which allows individuals to cognitively separate from current tasks. Individuals can, and often do, access Facebook from home or work as well as social venues, meaning that Facebook appears to be a third place, within a third place.

However, the other three SNS were inconsistent regarding their representation of evolving third place characteristics. Based on data from this study, Snapchat appears to meet many of the evolving third place characteristics. Snapchat users check the SNS regularly, primarily use Snapchat to talk 
with existing friends, and the conversation is often reciprocal and playful. However, individuals do not often use Snapchat to initiate new relationships, and the conversation is usually limited to one's closest friends, which argue against third place characteristics. These results are somewhat consistent with Instagram, as users don't necessarily use the SNS to form new relationships or to communicate with others. Rather, Instagram users passively engage with the content, which offers a cognitive reprieve from the stress of everyday life, an attribute of evolving third places. Next, although McArthur and White (2016) found that Twitter conversations can be third places based on traditional third place characteristics with some caveats, the current study found more evidence that Twitter users do not access it as a third place compared to other SNS. Individuals primarily use Twitter to passively consume content or to publicize information, rather than socialize. It appears that Twitter may be used to be informed with the local, national, or international news or to promote or become aware of various events or details of a celebrity's life. Although the passive consumption and cognitive separation are representative of evolving third places, the lack of intentional sociability would argue against Twitter being an evolved third place based on current evolving characteristics.

Oldenburg and Brissett state that third places are "uniquely qualified to sustain a sense of wellbeing" (Oldenburg \& Brissett, 1982, p. 269). Third places provide opportunities for individuals to socially connect and build relationships, which in turn builds social capital, a factor beneficial for building community and interpersonal relationships. Although different from UGT, these third place characteristics are consistent with UGT based on how individuals use social media and the gratifications they receive from their social media experiences. Verification of the third place characteristics can be used in conjunction with UGT to illustrate the benefits of using social media for one's well-being. Some of these benefits include continuous access, mobility and the potential to engage reciprocally. Virtual third places may increase and add to the benefits of third places and support the human need to connect with others.

\section{LIMITATIONS AND CONCLUSIONS}

Although this research advances knowledge on third places and SNS, this study is not without its limitations. First, quantitative data was self-reported from a sample that was not diverse in terms of gender, ethnicity, or location. Details about participants' social media use, such as how they participated in social media activities, were also not collected. It is important then to note the limited potential of these findings as they pertain to the motivation for using social media. A larger sample size and more precise indication of motivations for using social media would increase the potential of these study results for the wider society. Additionally, research needs to address the interface of virtual third places with the physical environment as well as the impact of one upon the other. For example, does one enhance the other by increasing sociability? A question that McArthur (2016) also raises, do virtual third places allow humans to be in two "places" at the same time? Future studies are encouraged to examine the benefits of this multi-level experience of third places.

Oldenburg and Brissett (1982) offered the third place as a solution to changing twentieth-century socializing trends. As virtual and physical space interface in human socializing practices, the findings of this study provide insights into understanding how, why, and where individuals seek relationships. As evidenced in this study, third places may not equate to a specific physical location. Moreover, virtual environments may have some of the same social benefits as physical third places. Further research needs to develop this concept, and in particular, address and expand theory that underpins human experience in virtual third places. 


\section{REFERENCES}

Bargh, J. A., \& McKenna, K. Y. A. (2004). The Internet and social life. Annual Review of Psychology, 55(1), 573-590. doi:10.1146/annurev.psych.55.090902.141922 PMID:14744227

Billedo, C. J., Kerkhof, P., \& Finkenauer, C. (2015). The use of social networking sites for relationship maintenance in long-distance and geographically close romantic relationships. Cyberpsychology, Behavior, and Social Networking, 18(3), 152-157. doi:10.1089/cyber.2014.0469 PMID:25751046

Blight, M. G., Ruppel, E. K., \& Schoenbauer, K. V. (2017). Sense of community on Twitter and Instagram: Exploring the roles of motives and parasocial relationships. Cyberpsychology, Behavior, and Social Networking, 20(5), 314-319. doi:10.1089/cyber.2016.0505 PMID:28498041

Bosker, B. (2014, July 14). Study shows how people use Snapchat - and it's not sexting. Huffpost. Retrieved from https://www.huffingtonpost.com/2014/07/14/snapchat-sexting-study_n_5574642.html

Boyarsky, K. (2017). How do people use Twitter? [Infographic]. Hubspot. Retrieved from https://blog.hubspot. com/marketing/twitter-usage-stats

Bryant, F. B., \& Yarnold, P. R. (1995). Principal-components analysis and exploratory and confirmatory factor analysis. In L. G. Grimm \& P. R. Yarnold (Eds.), Reading and understanding multivariate statistics (pp. 99-136). American Psychological Association.

Carson, B. (2016, March 25). Snapchat users now spend 25 to 30 minutes every day on the app, and it's trying to attract the TV money because of it. Business Insider. Retrieved from https://www.businessinsider.com/howmuch-time-people-spend-on-snapchat-2016-3

Chen, B. (2015, April 5). What is Instagram's mission and vision statement? Quora. Retrieved from https:// www.quora.com/What-is-Instagrams-mission-and-vision-statement

Ducheneaut, N., Moore, R. J., \& Nickell, E. (2007). Virtual third places: A case study of sociability in massively multiplayer games. Journal of Collaborative Computing, 16(1-2), 129-166. doi:10.1007/s10606-007-9041-8

Duggan, M., Ellison, N. B., Lampe, C., Lenhart, A., \& Madden, M. (2015, January 9). Frequency of social media use. Pew Research Center. Retrieved from https://www.pewinternet.org/2015/01/09/frequency-of-socialmedia-use-2/

Dumas, T. M., Maxwell-Smith, M., Davis, J. P., \& Giulietti, P. A. (2017). Lying or longing for likes? Narcissism, peer belonging, loneliness and normative versus deceptive like-seeking on instagram in emerging adulthood. Computers in Human Behavior, 71, 1-10. doi:10.1016/j.chb.2017.01.037

Ellison, N. B., Steinfield, C., \& Lampe, C. (2007). The benefits of Facebook "friends:" Social capital and college students' use of online social network sites. Journal of Computer-Mediated Communication, 12(4), 1143-1168. doi:10.1111/j.1083-6101.2007.00367.x

Facebook. (2018, September). Stats. Facebook Newsroom. Retrieved from http://newsroom.fb.com/company-info/

Fox, J., Warber, K. M., \& Makstaller, D. C. (2013). The role of Facebook in romantic relationship development: An exploration of Knapp's relational stage model. Journal of Social and Personal Relationships, 30(6), 771-794. doi: $10.1177 / 0265407512468370$

Hsu, C., Wang, C., \& Tai, Y. (2011). The closer the relationship, the more interaction on Facebook? Investigating the case of Taiwan users. Cyberpsychology, Behavior, and Social Networking, 14(7-8), 473-476. doi:10.1089/ cyber.2010.0267 PMID:21288075

Lambert, A. (2016). Intimacy and social capital on Facebook: Beyond the psychological perspective. New Media \& Society, 18(11), 2559-2575. doi:10.1177/1461444815588902

Langlais, M. R., \& Vaux, D. E. (in press). Measuring the "thirdplaceness" of social media platforms. In D. E. Vaux \& D. Wang (Eds.), Research Methods for Interior Design: Applying Interiority. Routledge Publishers, Inc.

LeFebvre, L., Blackburn, K., \& Brody, N. (2015). Navigating romantic relationships on Facebook: Extending the relationship dissolution model to social networking environments. Journal of Social and Personal Relationships, 32(1), 78-98. doi:10.1177/0265407514524848 
Lenhart, A. (2015, April 5). Teens, social media, and technology overview 2015. Pew Research Center. Retrieved from https://www.pewinternet.org/2015/04/09/teens-social-media-technology-2015/

McArthur, J. A. (2016). Digital proxemics: How technology shapes the ways we move. Peter Lang. doi:10.3726/978-1-4539-1724-4

McArthur, J. A., \& White, A. F. (2016). Twitter chats as third places: Conceptualizing a digital gathering site. Social Media + Society, 2(3), 1-9. doi:10.1177/2056305116665857

Memarovic, N., Fels, S., Anacleto, J., Calderon, R., Gobbo, F., \& Carroll, J. M. (2014). Rethinking third places: Contemporary design with technology. The Journal of Community Informatics, 10(3), 1-12. doi:10.15353/joci. v10i3.3440

Newton, C. (2017, September 14). Snapchat's Bitmoji avatars are now three-dimensional and animated. The Verge. Retrieved from https://www.theverge.com/2017/9/14/16303504/snapchat-bitmoji-world-lenses-animation-gabsee

Oldenburg, R. (1999). The great good place: Cafes, coffee shops, bookstores, bars, hair salons and other hangouts at the heart of the community. Marlowe \& Company.

Oldenburg, R., \& Brissett, D. (1982). The third place. Qualitative Psychology, 5(4), 265-284. doi:10.1007/ BF00986754

Park, N., Jin, B., \& Jin, S. A. (2011). Effects of self-disclosure on relational intimacy in Facebook. Computers in Human Behavior, 27(5), 1974-1983. doi:10.1016/j.chb.2011.05.004

Pew Research Center. (2018, February 5). Social media fact sheet. Retrieved from https://www.pewinternet. org/fact-sheet/social-media/

Phua, J., Jin, S. V., \& Kim, J. (2017). Uses and gratifications of social networking sites for bridging and bonding social capital: A comparison of Facebook, Twitter, Instagram, and Snapchat. Computers in Human Behavior, 72, 115-122. doi:10.1016/j.chb.2017.02.041

Piwek, L., \& Joinson, A. (2016). 'What do they Snapchat about?' Patterns of use in time-limited instant messaging service. Computers in Human Behavior, 54, 358-367. doi:10.1016/j.chb.2015.08.026

Punyanunt-Carter, N. M., De La Cruz, J. J., \& Wrench, J. S. (2017). Investigating the relationships among college students' satisfaction, addiction, needs, communication apprehension, motives, and uses \& gratifications with Snapchat. Computers in Human Behavior, 75, 870-875. doi:10.1016/j.chb.2017.06.034

Purnell, D. (2015). Expanding Oldenburg: Homes as third places. Journal of Place Management and Development, 8(1), 51-62. doi:10.1108/JPMD-03-2014-0006

Putnam, R. D., \& Feldstein, L. M. (2003). Better together. Simon \& Schuster.

Rao, V. (2008). Facebook applications and playful mood: The construction of Facebook as a "third place". MindTrek '08: Proceedings of the 12th International Conference on Entertainment and Media in the Ubiquitous Era, 8-12. doi:10.1145/1457199.1457202

Rheingold, H. (1993). The Virtual Community: Homesteading on the Electronic Frontier. HarperCollins.

Rosenstiel, T., Sonderman, J., Loker, K., Ivancin, M., \& Kjarval, N. (2015, September 1). How people use Twitter in general. American Press Institute. Retrieved from https://www.americanpressinstitute.org/publications/reports/ survey-research/how-people-use-twitter-in-general/

Ruggiero, T. E. (2000). Uses and gratifications theory in the 21 st century. Mass Communication \& Society, 3(1), 3-37. doi:10.1207/S15327825MCS0301_02

Sheldon, K. M., Abad, N., \& Hirsch, C. (2011). A two-process view of Facebook use and relatedness need satisfaction: Disconnection drives use, and connection rewards it. Journal of Personality and Social Psychology, 100(4), 766-775. doi:10.1037/a0022407 PMID:21280967

Sheldon, P. (2008). The relationship between unwillingness-to-communicate and students' Facebook use. Journal of Media Psychology, 20(2), 67-75. doi:10.1027/1864-1105.20.2.67

Shen, C., \& Chen, W. (2015). Gamers' confidants: Massively Multiplayer Online Game participation and core networks in China. Social Networks, 40, 207-214. doi:10.1016/j.socnet.2014.11.001 
Sinclair, T. J., \& Grieve, R. (2017). Facebook as a source of social connectedness in older adults. Computers in Human Behavior, 66, 363-369. doi:10.1016/j.chb.2016.10.003

Smith, K. (2016, May). Marketing: 47 Facebook. Stat, 2016. https://www.brandwatch.com/blog/47-facebookstatistics-2016/

Snapchat. (2017). Snap Inc. Retrieved from https://www.snap.com/en-US/

Soukup, C. (2006). Computer-mediated communication as a virtual third place: Building Oldenburg's great good places on the World Wide Web. New Media \& Society, 8(3), 421-440. doi:10.1177/1461444806061953

Steinkuehler, C. A., \& Williams, D. (2006). Where everybody knows your (screen) name: Online games as "third places". Journal of Computer-Mediated Communication, 11(4), 885-909. doi:10.1111/j.1083-6101.2006.00300.x

Tabachnick, B. G., \& Fidell, L. S. (2007). Using multivariate statistics (5th ed.). Allyn and Bacon.

Vaterlaus, J. M., Barnett, K., Roche, C., \& Young, J. A. (2016). 'Snapchat is more personal': An exploratory study on Snapchat behaviors and young adult interpersonal relationships. Computers in Human Behavior, 62, 594-601. doi:10.1016/j.chb.2016.04.029

Vaux, D. (2014). Interior people places: The impact of the built environment on the third place experience. In J. Thompson \& N. Blossom (Eds.), Handbook for Interior Design. Wiley-Blackwell.

Vaux, D. E., \& Langlais, M. R. (2021). An update of third place theory: Evolving third place characteristics represented in Facebook. International Journal of Technology and Human Interaction, 17(4), 117-130. doi:10.4018/IJTHI.2021100107

Waxman, L. (2006). The coffee shop: Social and physical factors influencing place attachment. Journal of Interior Design, 31(3), 35-53. doi:10.1111/j.1939-1668.2006.tb00530.x

Wellman, B., \& Gulia, M. (1999). Net surfers don't ride alone: Virtual communities as communities. In B. Wellman (Ed.), Networks in the Global Village (pp. 331-366). Westview. Retrieved from http://groups.chass.utoronto. $\mathrm{ca} /$ netlab/wp-content/uploads/2012/05/Net-Surfers-Dont-Ride-Alone-Virtual-Community-as-Community.pdf

Westen, D., \& Rosenthal, R. (2003). Quantifying construct validity: Two simple measures. Journal of Personality and Social Psychology, 84(3), 608-618. doi:10.1037/0022-3514.84.3.608 PMID:12635920

Wright, S. (2012). From "third place" to "third space": Everyday political talk in non-political online spaces. Javnost - The Public, 19, 5-20. 10.1080/13183222.2012.11009088

Wuthnow, R. (1999). The Culture of Discontent. In N. J. Smelser \& J. C. Alexander (Eds.), Diversity and Its Discontents. Princeton University Press.

Zephoria Digital Marketing. (2016, November). The Top 20 Valuable Facebook Statistics. Retrieved from https:// zephoria.com/top-15-valuable-facebook-statistics/

\footnotetext{
Michael Langlais received his PhD in Human Development and Family Sciences from the University of Texas in Austin and is currently Teaching Faculty at Florida State University. His research focuses on promoting the healthy formation and maintenance of romantic relationships, with a specific emphasis on the role of technology for these processes.
}

Dana E. Vaux is Assistant Professor and Program Director of Interior \& Product Design at the University of Nebraska Kearney. Her research focuses on the impact of place theory on current culture from a historical perspective. 